\title{
Authors' Reply to Friesen: “An Extension of Janmahasatian's Fat-Free Mass Model for Universal Application Across Populations of Different Ethnicities"
}

\author{
Jaydeep Sinha ${ }^{1,2} \cdot$ Hesham S. Al-Sallami ${ }^{1}$ - Stephen B. Duffull ${ }^{1}$
}

Published online: 22 May 2020

(c) Springer Nature Switzerland AG 2020

We thank Friesen for introducing equation (Eq. 1) as a "generalized weight scaler (WS)" [1] using our extended fat-free mass (FFM) model in an Indian population $\left(F F M_{E x t, I n d}\right)$ [2].

$W S=W T \times\left(\frac{22}{B M I}\right)^{s}$,

where $S=0.28$ for the Indian population.

Notably, the concept of the "generalised weight scalar" actually represents the predicted normal weight (PNWT) that was originally conceived much earlier [3], where a model to predict PNWT was developed by using an empirical FFM model that was available at that time. Therefore, Freisen's effort to propose an updated equation for what is essentially PNWT (termed as "generalised weight scalar") using the currently available semi-mechanistic FFM models $[2,4]$ is appreciated. Friesen has also cited the relevance of using a PNWT concept over FFM when using a conventional ' $\mathrm{mg} / \mathrm{kg}$ ' dosing. However, we note that for those settings where the dosing size was FFM, then the generalised weight scalar (and PNWT) should not be used.

Our purpose in writing this response is to make it clear to the readers that the structural model proposed in the letter (Eq. 1) represents a model essentially to approximate PNWT and should not be interpreted as a simpler alternative to the $F F M_{E x t}$ models reported in our article. Predicted

This reply refers to the article available at https://doi.org/10.1007/ s40262-020-00905-y.

Stephen B. Duffull

stephen.duffull@otago.ac.nz

1 School of Pharmacy, University of Otago, 18 Frederick St, Dunedin, New Zealand

2 Present Address: Division of Pharmacotherapy and Experimental Therapeutics, Eshelman School of Pharmacy, University of North Carolina, Chapel Hill, NC, USA normal weight and FFM are two different measures of body size, where PNWT is larger than FFM as it includes normal fat mass and for Indian male and female individuals is 1.3185-fold and 1.5754-fold higher than FFM. For the purpose of developing population-specific FFM models (e.g. $\left.\mathrm{FFM}_{\text {Ext,Ind }}\right)$, the readers are encouraged to use the $F F M_{E x t}$ equations described in our article [2].

\section{Compliance with Ethical Standards}

Funding No funding was received for the preparation of this response.

Conflict of Interest Jaydeep Sinha, Hesham S Al-Sallami, and Stephen B. Duffull have no conflicts of interest that are directly relevant to the content of this response.

Ethics Approval No ethical approval was required for the preparation of this response.

\section{References}

1. Friesen JHP. Comment on: “An Extension of Janmahasatian's FatFree Mass Modelfor Universal Application Across Populations of Different Ethnicities". Clin Pharmacokinet. 2020. https://doi. org/10.1007/s40262-020-00905-y.

2. Sinha J, Al-Sallami HS, Duffull SB. An extension of Janmahasatian's fat-free mass model for universal application across populations of different ethnicities. Clin Pharmacokinet. 2020. https:// doi.org/10.1007/s40262-020-00883-1.

3. Duffull SB, Dooley MJ, Green B, Poole SG, Kirkpatrick CM. A standard weight descriptor for dose adjustment in the obese patient. Clin Pharmacokinet. 2004;43(15):1167-78.

4. Janmahasatian S, Duffull SB, Ash S, Ward LC, Byrne NM, Green B. Quantification of lean bodyweight. Clin Pharmacokinet. 2005;44(10):1051-65. 